\title{
Sondas nasogástricas e nasoentéricas: como diminuir o desconforto na instalação?
}

\author{
NASOGASTRIC AND NASOENTERIC FEEDING TUBES: \\ HOW MAY THE DISCOMFORT DURING PLACEMENT BE REDUCED?
}

SONDAS NASOGÁSTRICAS Y NASOENTÉRICAS:

CÓMO DISMINUIR EL DISCONFORT EN LAINSTALACIÓN?

\section{Adriano Menis Ferreira ${ }^{1}$}

Estima-se que aproximadamente 1 milhão de sondas nasogástricas (NG) e nasoenterais (NE) são instaladas anualmente em adultos e crianças nos Estados Unidos ${ }^{(1)}$. No Brasil não se dispõe de tais dados, mas acredita-se que este procedimento seja comum na maior parte das instituições prestadoras de serviços de assistência à saúde.

No ano de 1999, o Ministério da Saúde (MS), através da Portaria 337 e da Resolução 63 de 2000, normatizou a Terapia Nutricional Enteral e oficializou as atribuições de cada profissional dentro da equipe multiprofissional especializada ${ }^{(2)}$. Em relação as ações de enfermagem, a Resolução 162 do Conselho Federal de Enfermagem publicada em 1993, dispõe sobre a administração da nutrição parenteral e enteral sendo que nesta última cabe ao enfermeiro, dentre outras atribuições, introduzir a sonda, bem como determina a Portaria do MS.

Vários são os procedimentos para instalação de sondas NG e NE. No entanto em um destes passos, ou seja, a introdução da sonda, percebe-se um desconforto por parte dos pacientes, que resulta as vezes em vômitos e até recusa do procedimento. Este fato é confirmado por estudos ${ }^{(3)}$ onde constataram que a inserção de sonda nasogástrica foi o procedimento mais doloroso identificado por pacientes e médicos. A dor referida, na população estudada, foi pior do que a sentida em drenagem de abscesso, redução de fratura e cateterização uretral.

Comumente utiliza-se anestésico em forma de gel para facilitar a introdução de sondas, no entanto quando se trata de sondas NG e NE o único objetivo é facilitar o deslizamento da sonda pela narina, uma vez que o anestésico é passado ao redor da sonda no momento da introdução e não previamente na narina, sendo assim, insuficiente o tempo de contato para que haja anestesia local. Desta forma fica evidente que o desconforto ocorrerá.

Para diminuir o desconforto e trauma na inserção de sondas NG e NE outras alternativas são propostas e implementadas. A inalação de lidocaína por meio de nebulização, spray e respiração intermitente com pressão positiva através de nebulização pela boca, tem demonstrado redução significativa da dor associada a instalação de sonda nasogástrica ${ }^{(4)}$.

Em 20041 ${ }^{(4)}$ randomizou-se 50 pacientes adultos em dois grupos iguais que necessitavam de sondas $\mathrm{NG}$ em duas unidade de emergência. O grupo experimental $(\mathrm{N}=29)$ recebeu $4 \mathrm{ml}$ de lidocaína $10 \%$ (400mg de lidocaína) introduzido pelo nariz e faringe por meio de uma máscara de nebulização com fluxo de oxigênio de $6 \mathrm{~L} / \mathrm{min}$. Os pacientes foram orientados a respirarem pela boca e nariz durante a nebulização. O grupo placebo $(\mathrm{N}=21)$ recebeu nebulização de solução salina. Vasoconstritores não

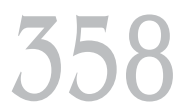

Rev Esc Enferm USP

2005; 39(3):000-00. 
foram usados. As enfermeiras da unidade instalaram sondas nasogástricas número $18 \mathrm{~F}(5,94 \mathrm{~mm})$ usando gel lubrificante a base de água. O desconforto dos pacientes foi mensurado através de uma escala visual analógica de $100 \mathrm{~mm}$ onde em uma extremidade havia a marca de nenhum desconforto e na outra extremidade desconforto máximo que os mesmos sentiram durante o procedimento, sendo a dificuldade de inserção da sonda avaliada pelas enfermeiras usando escala tipo Likert de 5 pontos, caracterizando a dificuldade em mínima, leve (menos difícil do que o usual), moderada (dificuldade habitual), substancial (maior dificuldade do que o habitual) e extrema. Houve uma diferença clínica e estatisticamente significante no desconforto dos pacientes associado com a passagem da sonda nasogástrica entre o grupo experimental e placebo (média do escore da escala 37.7 x $59.3 \mathrm{~mm}$, respectivamente; $95 \%$ de intervalo de confiança). Não houve diferença na dificuldade da instalação da sonda entre os dois grupos. No entanto, epistaxe ocorreu mais freqüentemente no grupo experimental $(17 \%$ versus $0 \%, 95 \mathrm{CI})$.

Este estudo mostrou, dentre outros citados pelos autores, que a lidocaína nebulizada para o nariz e faringe por meio de nebulização diminuí o desconforto decorrente da inserção de sonda nasogástrica e deve ser considerado antes de implementar o procedimento ${ }^{(4)}$. Se a incidência de epistaxe no grupo experimental é causada pela lesão na mucosa anestesiada, e nesse caso, se isso pode ser reduzido com vasoconstrictores, permanece sem resposta e requer pesquisas afim de obte-las.

\section{REFERÊNCIAS}

(1) Ellett MLC. What is known about methods of correctly placing gastric tubes in adults and children. Gastroenterol Nurs 2004; 27(6):253-9.

(2) Unamuno MRDL, Marchini JS. Sonda nasogástrica/ nasoentérica: cuidados na instalação, na administração da dieta e prevenção de complicações. Medicina (Ribeirão Preto) 2002; 35(1):95-101.

(3) Singer AJ, Richman PB, Kowalska A, Thode HC Jr.
Comparison of patient and practitioner assessments of pain from commonly perfomed emergency department procedures. Ann Emerg Med 1999; 33(6):652-8.

(4) Cullen L, Taylor D, Taylor S, Chu K. Nebulized lidocaine decreases the discomfort of nasogastric tube insertion: a randomized, double-blind trial. Ann Emerg Med 2004; 44(2):131-7.
Sentimento de impotência: diferenciação de outros diagnósticos e conceitos
Correspondência: Adriano Menis Ferreira Rua Prof. Enjolrras Vampre, 240 - Ap. 22 São Manoel CEP -15091-290 - ?? 